\title{
Treatment of urethral strictures in balanitis xerotica obliterans (BXO) using circular buccal mucosal meatoplasy: Experience of 15 cases
}

\author{
Abdulmuttalip Simsek ${ }^{1}$, Sinasi Yavuz $\mathrm{Onol}^{2}$, Omer Kurt ${ }^{3}$ \\ ${ }^{1}$ Bakırkoy Dr. Sadi Konuk Training and Research Hospital, Department of Urology Istanbul, Turkey; \\ ${ }^{2}$ Bezmi Alem Vakıf University, Department of Urology, Istanbul, Turkey; \\ ${ }^{3}$ Bayrampasa State Hospital, Department of Urology, Istanbul, Turkey.
}

\begin{abstract}
Summary Objectives: Balanitis xerotica obliterans (BXO) related strictures involving the external urethral meatus. We reviewed our result with the use of circular mucosal graft in the reconstruction of strictures.

Methods: Between March 1997 and January 2012, 15 patients underwent circular buccal mucosal urethroplasy for BXO related anterior urethral strictures. Urethral catheter was removed within 2 weeks.

Follow-up included patient symptoms assessment, cosmetic outcome and uroflowmetry.

Results: Median follow-up was 20.5 months (range 4 to 96). Mean postoperative peak urinary flow rate obtained 1 month after catheter removal was $22.4 \mathrm{ml}$ per second. All patients had a normal meatus and none had recurrent stricture, chordee or erectile dysfunction. A functional and cosmetic outcome was achieved in $100 \%$ of the patients.

Conclusions: Circular mucosal graft technique for treatment of meatal strictures is an efficient method for the restoration of a functional and cosmetic penis.
\end{abstract}

KEY WORDS: Buccal mucosa; BXO; Urethral stricture; Meatoplasty.

Submitted 16 September 2013; Accepted 5 October 2013

\section{INTRODUCTION}

The term balanitis xerotica obliterans (BXO) was first described by Stuhmer in 1928, for the chronic, progressive scleroatrophic inflammatory process of unknow etiology affecting the glans penis, prepuce and urethral meatus. The lesions occur as plaques or papules on the glans penis and result in urethral meatal stenosis (1). BXO has been managed both medically and surgically. Medical treatment can provide useful palliation but is generally regarded to be limited. The surgical options are more definitive, and include circumcision, dilatation or surgically correction of meatal stenosis and some urethroplasty techniques $(2,3)$. A large veriety of free extragenital graft tissues have been used for urethroplasty such as bladder mucosa, buccal mucosa, vein and appendix (4). Humby was the first to describe the use of buccal mucosa for the urethral substitution (5). The glandular urethra is unique in that it is most undistensible and the narrowest portion of the urethra. When strictured, this portion becomes extremely narrow. We describe our reconstructive technique for $\mathrm{BXO}$ using circular buccal mucosal graft urethroplasty.

\section{MATERIALS AND METHOdS}

Between 1997 and 2012, 15 patients with a mean age of 39.3 years (range 36 to 49 ) with meatal stenosis underwent circular buccal mucosal substitution urethroplasty in our department. All patients were subjected to preoperative urine culture, uroflowmetry and retrograde urethrogram to document the severity and length of the stricture. Stricture etiology was balanitis xerotica obliterans in all patients. All had previously undergone a number of dilatations, the average number of prior formal surgical prosedures was 1.4 (including meatotomy and urethral dilatation). Most cases had symptoms of hesitancy, intermittent urine stream, decreased caliber of urine stream, incomplete bladder emptying, nocturia, pain with voiding or even urinary retention. Inclusion criteria included BXO and strictures length $<2 \mathrm{~cm}$. Exclusion criteria were unhealthy oral cavity, urinary tract infection, strictures length $>2 \mathrm{~cm}$ and loss of follow-up. In this study mean duration of disease was $13.3 \pm 4.9$ months.

Uroflowmetry demonstrated urinary peak flows ranging from $2.5 \mathrm{ml} / \mathrm{s}$ and $14 \mathrm{ml} / \mathrm{s}$ (mean $4.18 \mathrm{ml} / \mathrm{s}$ ).

Preoperatively, 15 patients underwent suprapubic cystostomy and 3 patients presented with urethrocutaneous fistulae. The catheter was removed 2 weeks after the meatoplasty. The patients were advised self meatal calibration with a 16 F Foley catheter two times in a week for 1 month. At each visit of follow up, patient symptoms assessment, cosmetic outcome and uroflowmetry was done. At 6- month follow up calibration of distal penile urethra with 16 F Foley catheter was also done to evaluate urethral lumen. 


\section{Operative technique}

All cases were performed by the same surgeon (SYO). The patient was placed in a standard supine position on the operating table. All surgeries were performed under general anesthesia and a circular submeatal incision was made (Figure 1). Bad stricture tissue was mobilized until the proximal extent extending about $1 \mathrm{~cm}$ into the healthy segment. Incision of the stricture was performed, the length of the strictured urethra was measured and the incision was extended at least $0.5 \mathrm{~cm}$ into the healthy urethral tissue. A buccal mucosa graft was harvested from one or both cheeks and lower lip using a standard technique. For meatal reconstruction the circular buccal mucosa graft was sutured to the dorsally cut margins of the meatus using a 4-5-zero monofilament suture (Figure 2). The patients were discharged from the hospital on first or second postoperative day.

\section{Figure 1.}

The strictured meatus was circular incised and bad stricture tissue was mobilized until healthy segment appeared.

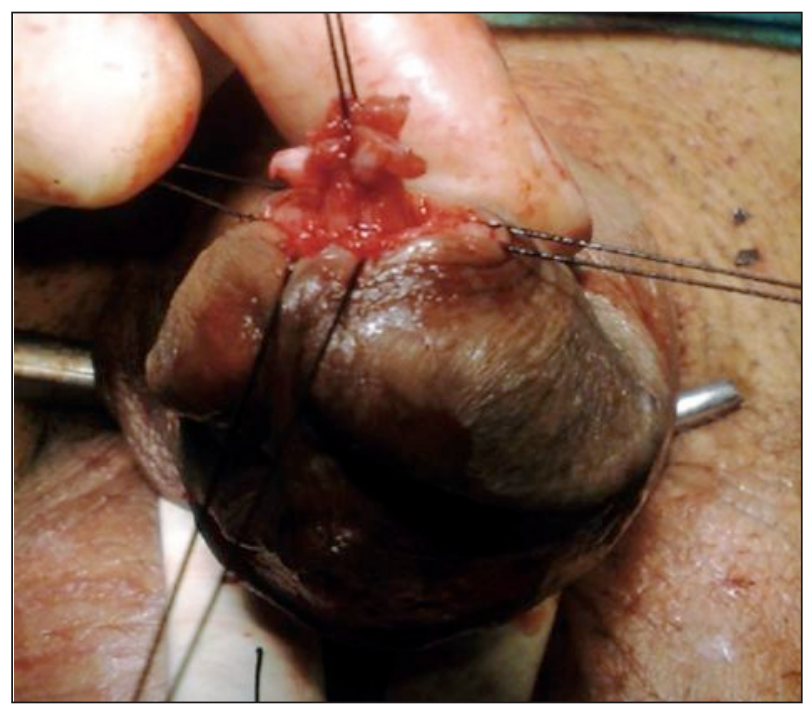

Figure 2.

The circular buccal mucosa graft was sutured to the dorsally margins of the meatus using a 4-5-zero monofilament on the Benique dilator.

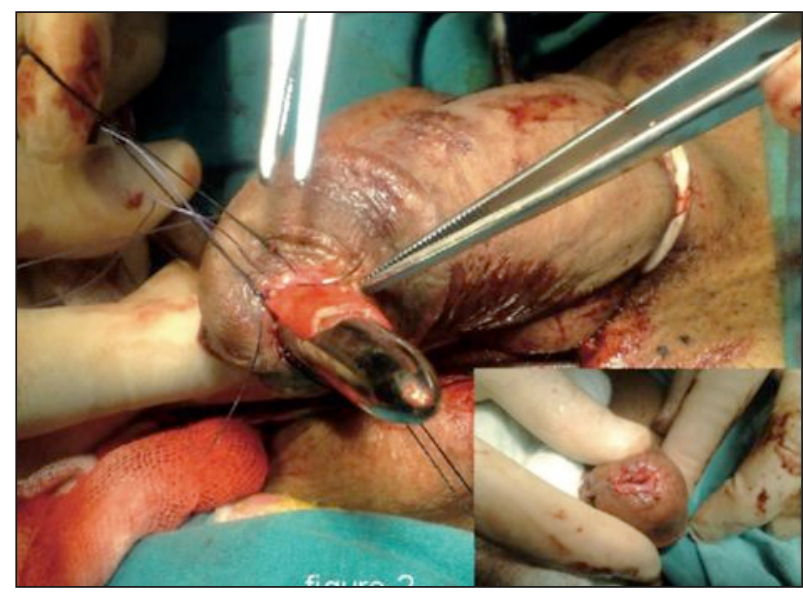

\section{RESULTS}

After catheter removal 3 patients did not come to control. Therefore, these patients were excluded from this study. Stricture length was less than $2.0 \mathrm{~cm}$ in all cases (range 0.5 to 1.6 ). Mean operation duration was 45 minutes. Patients were followed for a median of 20.5 months (range 4 to 96). Durable functional and cosmetic outcome was obtained in all cases. We did not use any of cosmetic outcomes scale. However, not only patients opinion but also surgeons point of view is important for evaluation of cosmetic outcomes. We noticed no significant complications with this technique. Mean postoperative peak urinary flow rate obtained 1 month after catheter removal was $22.4 \mathrm{ml}$ per second (range 16 to 38). There were no recurrent strictures or obstructive voiding symptoms during follow up (Table 1).

\begin{tabular}{|lcc|}
\hline Characteristics & Mean & Range \\
\hline Age $(\mathrm{y})$ & 39.3 & $36-49$ \\
\hline Stricture length $(\mathrm{cm})$ & 1.4 & $0.5-1.6$ \\
\hline Graft length $(\mathrm{cm})$ & 1.8 & $0.8-2.4$ \\
\hline Operative time $(\mathrm{min})$ & 45 & $28-94$ \\
\hline Preoperative peak flow rate $(\mathrm{ml} / \mathrm{sn})$ & 4.18 & $2.5-14$ \\
\hline $\begin{array}{l}\text { Postoperative peak flow rate }(\mathrm{ml} / \mathrm{s}) \\
\text { (at 1 mo) }\end{array}$ & 22.4 & $16-38$ \\
\hline Follow up $(\mathrm{mo})$ & $\begin{array}{c}\text { 24.6 } \\
\text { (meadian, 20.5) }\end{array}$ \\
\hline
\end{tabular}

Table 1.

Patient characteristics $(n=15)$.

\section{Discussion}

Glandular strictures are difficult to treat and are sometimes associated with recurrence. The glans becomes inelastic and shows significant scarring, especially in patients of BXO. Strictures involving the distal urethra and fossa navicularis are particularly challenging because successful reconstruction requires the creation of a functional urethral conduit as well as maintaining a cosmetically appealing glans penis. Treatment of distal urethral strictures developed in the last decades from dilatation, internal urethrotomy to definitive reconstruction techniques such as penile fasciocutaneous flap urethroplasty and buccal mucosa graft urethroplasty $(6,7)$.

Urethral meatal stenosis can be treated by ventral meatotomy or dorsal V-meatoplasty. Meatotomy in BXO is often followed by restenosis. Surgical correction of the meatus, however does not improve the common loss of sensitivity in the glans penis. Zungri et al., reported that a complete resection of the glans mucosa and meatoplasty produced complete resolution of the disease in their cases (8). Penile skin flap urethroplasty has been used for 1-stage reconstruction of BXO strictures with encouraging short term results (9-11). However the long term outcomes of this technique have been uniformly disappointing $(12,13)$ Venn and Mundy reported an almost $100 \%$ recurrence rate for 1 -stage urethroplasy with genital skin flap (12). In their series all patients with penile 
skin reconstruction had failure within 2 years with evidence of BXO. Ramon et al. reported that using ventral transverse penile skin island flap an overall success rate of $83 \%$ with a mean long-term follow-up of 10.2 years (14). We have previously investigated the use of transverse island fasciocutaneous penile flap for reconstruction of strictures of the fossa navicularis and meatus with positive functional and cosmetic outcome in 96\% after a mean follow up of 30.2 months (range 4 to 96) (15). Deepak Dubey et al. reported buccal mucosal urethroplasy for BXO related urethral strictures. They investigated 1-stage dorsal onlay and 2-stage buccal mucosal urethroplasty for strictures. Patients with a severely scarred urethral plate,focally dense segments or active infection underwent 2-stage urethroplasty (16).

Our results demonstrate that circular buccal mucosal meatoplasty provides satisfactory results in selected cases of BXO related anterior urethral strictures. Circular buccal mucosal graft can be successfully used for reconstructive distal urethral segment including the meatus. To our knowladge prior to this study there have been no reports in the literature describing circular buccal mucosal graft reconstruction urethral strictures for BXO. Goel et al. presented their experience with 10 patients with glandular or meatal strictures treated with double buccal mucosal graft technique. They reported a functional and cosmetic outcome in $100 \%$ of patients presenting with anterior urethral stricture (range length 4-6.5 cm) after a mean follow-up of 13.5 months (17). Palminteri et al. described the use of buccal mucosa graft both on the dorsal and ventral aspects in cases of severe bulbar urethral strictures with good results (18). The main long term donor site complications included intraoperative hemorrahage, postoperative infection, pain, swelling, damage to the parotid duct, limitations of oral opening and loss or altered sensation of the cheek and lower lip (19).

Therefore some reconstructive surgeons advocate a 2stage approach involving excision of the diseased urethra and buccal mucosal grafting, followed by stage 2 urethroplasty after 4 to 6 months $(12,13)$. Patients with anterior urethral stricture need lip mucosa and cheek mucosa for urethroplasty and therefore have more morbidity in the form of scar contracture and lip deviation or retraction and long lasting paresthesia and numbness of the lower lip. However in our practice, only 1 patient had a lip retraction and there was no another complication.

To our knowledge, this is the largest series of buccal mucosal graft urethroplasties used for repairing anterior urethral strictures. The overall success rate in our series was $100 \%$, which included the repair of meatus in the process of BXO. The results of our study have shown that the circular mucosal graft can be suitable as the transverse island fasciocutaneous penile flap for the reconstruction of anterior urethral strictures. Circular buccal mucosal graft urethroplasy is easy harvesting and with minimal donor site complications.

\section{RefERENCES}

1. Stuhmer, A. Balanitis xerotica obliterans (post operationem) und ihre Beziehungen zur "Kraurosis glandis et praeputii penisf. Archiv fur Dermatologie und Syphilis. 1928; 156:613-623.
2. Wright JE. The treatment of childhood phimosis with topical steroid. Australian NZ J Surg. 1994; 64:327-8.

3. Fischer GO. Lichen sclerosus in childhood. Australasian J Dermatol. 1995; 36:166-7.

4. Dessanti A, Rigamonti W, Merulla V, et al. Autologous buccal mucosa graft for hypospadias repair: An initial report. J Urol. 1992; 147:1081-1084.

5. Humby G. A one-stage operation for hypospadias. Br J Surg. 1941; 29:84-92.

6. Jordan GH. Reconstruction of the fossa navicularis. J Urol. 1987; 138:102-4

7. Armenakas NA, Morey AF, McAninch JW. Reconstruction of resistant strictures of the fossa navicularis and meatus. J Urol. 1998; 160:359-63.

8. Zungri E, Chéchile G, Algaba F, Mallo N. Balanitis xerotica obliterans: surgical treatment. Eur Urol. 1988; 14:160-162.

9. Armenakas NA, Morey AF, McAninch JW. Reconstruction of resistant strictures of the fossa navicularis and meatus. J Urol. 1998; 160:359.

10. Wessels H, Morey AF, McAninch JW. Single-stage reconstruction of complex anterior urethral strictures: combined tissue transfer techniques. J Urol. 1997; 157:1271.

11. Morey AF, Tran LK, Zinman LM. Q-flapreconstruction of panurethral strictures. BJU Int. 2000; 86:1039.

12. Venn SN, Mundy AR. Urethroplasty for balanitis xerotica obliterans. BJU Int. 1998; 81:735.

13. Depasquale I, Park AJ, Bracka A. The treatment of balanitis xerotica obliterans. BJU Int. 2000; 86:459.

14. Virasoro R, Eltahawy EA, Jordan GH. Long-term follow-up for reconstruction of strictures of the fossa navicularis with a single technique. BJU Int. 2007; 100:1143-5.

15. Onol SY, Onol FF, Onur S, et al. Reconstruction of strictures of the fossa navicularis and meatus with transverse island fasciocutaneous penile flap. J Urol. 2008; 179:143.

16. Dubey D, Sehgal A, Srivastava A, et al. Buccal mucosal urethroplasty for balanitis xerotica obliterans related urethral strictures: the outcome of 1 and 2-stage techniques. J Urol. 2005; 173:463-6.

17. Goel A, Dalela D, Sankhwar SN. Meatoplasty using double buccal mucosal graft technique. Int Urol Nephrol. 2009; 41:885-7.

18. Palminteri E, Manzoni G, Berdondini E, et. al. Combined dorsal plus ventral double buccal mucosa graft in bulbar urethral reconstruction. Eur Urol. 2008; 53:81-90.

19. Bhargava S, Chapple CR. Buccal mucosal urethroplasty: Is it the new gold standard? Br J Urol. 2004; 93:1191-1193.

\section{Correspondence}

Abdulmuttalip Simsek, MD (Corresponding Author)

simsek76@yahoo.com

Department of Urology

Bakırkoy Dr. Sadi Konuk Training and Research Hospital

Tevfik Saglam Cad. No: 11 - 34000 Zuhuratbaba, Istanbul, Turkey

Sinasi Yavuz Onol, MD

Department of Urology - Bezmi Alem Vakif University, Istanbul, Turkey

Omer Kurt, MD

Department of Urology - Bayrampasa State Hospital, Istanbul, Turkey 